\title{
Phosphate coatings as a way to protect steel reinforcement from corrosion
}

\author{
Sergey Fedosov ${ }^{1}$, Varvara Roumyantseva², and Viktoriya Konovalova ${ }^{2, *}$ \\ ${ }^{1}$ Ivanovo State Polytecnic University, Sheremetevsky av., 21, Ivanovo, 153000, Russian Federation \\ ${ }^{2}$ Ivanovo State Polytecnic University, Department of nanotechnologies, physics and chemistry, \\ Sheremetevsky av., 21, Ivanovo, 153000, Russian Federation
}

\begin{abstract}
Phosphate coatings are successfully applied as a method of protecting steel products and structures from corrosion. Phosphate coatings mechanically prevent the entry of aggressive particles, such as chloride ions, to the surface of steel reinforcement. The parameters of corrosion rate of reinforcing steel in aggressive environment are determined by graphical method. The analysis of corrosion diagrams allows us to judge the effect of protective phosphate coatings on the kinetics of the corrosion process of steel reinforcement in environments of varying degrees of aggressiveness. The tests of the protective properties of phosphate coatings by contact corrosion method show that films with a finer crystal structure, as in modified phosphate coatings, are more resistant to anodic dissolution of steel. In parallel to determination of iron ions content in solutions the potential of steel reinforcement samples was measured. In samples protected by phosphate films, the potential change is not as sharp as in samples without coating, and the "dilution" of steel is slower. The study of anodic behavior of steel reinforcement of reinforced concrete, experimental study of the mass transfer mechanism of electrolyte supply to the surface of reinforced steel allow to develop practical recommendations to improve corrosion resistance and ensure the durability of reinforced concrete building materials.
\end{abstract}

\section{Introduction}

The service life of reinforced concrete structures can be divided into two separate phases. The first phase is the beginning of corrosion, in which the reinforcement is protected by a passive layer, but for some reasons this passivity can be impaired, for example, when carbonization or the penetration of chloride ions into a concrete coating take place. The second phase is the development of corrosion, which begins when the steel is de-passivated and ends when the limit value is reached, after which the effects of corrosion cannot be prevented [1, 2].

The duration of the initial phase depends on the thickness of the coating and the penetration rate of aggressive substances, as well as on the concentration necessary for the depassivation of steel. The penetration rate of aggressive substances depends on the quality of the concrete coating (porosity, permeability) and on microclimatic conditions (wet or dry) on the concrete surface [1, 3].

\footnotetext{
*Corresponding author: kotprotiv@yandex.ru
} 
After the destruction of the protective layer signs of corrosion in the form of rust immediately appear on the surface of the steel rods.

Corrosion rate is considered as the most important factor in the corrosion process from the point of view of safety and in the preparation of structural conservation programs. When the corrosion rate is very high the probability of collapse of the structure increases sharply and the safety of the structure decreases rapidly. The corrosion rate depends on various factors [4-8], so if it is possible to control these factors, then the corrosion rate will be negligible [3, 6]. Additional measures to protect the reinforcement from corrosion are usually used in cases where the structure is exposed to highly corrosive environments.

Phosphating has long been successfully used as a method of protecting metal products and structures from corrosion. The main advantage of phosphate film is that it has high corrosion resistance in all types of fuels, lubricants and organic oils, benzene, toluene and all gases except hydrogen sulfide. In addition to corrosion protection, metal phosphating is used as a basis for the application of varnishes, paints, adhesives, oils, waxes, etc. Phosphate coatings provide excellent adhesion, they «bind» organic coatings to the metal surface.

Cold metal phosphating is one of the best methods used to protect metal surfaces from corrosion and prepare its for painting $[9,10]$.

Phosphate coatings protect the reinforcement mechanically. They isolate the protected metal from the environment. In this case the porosity reduces the protective properties of coatings and there is a need to develop new solutions for coating with reduced porosity.

\section{Methods}

To study the properties, structure and composition of the studied materials (solid and liquid phases) before and after exposure to liquid corrosive environments, experimental studies were carried out using methods of chemical and physico-chemical analysis: electrometric method for measuring the $\mathrm{pH}$ of a medium; the method of contact corrosion; quantitative analysis of iron ions in an aqueous medium by the method of permanganatometry; chronopotentiometric measurement technique.

The researches were carried out using modern physical, physico-chemical and chemical methods of analysis and mathematical data processing. The error of the results does not exceed $3 \%$ with the permissible error of analytical methods $5 \%$. The reliability and validity of the results are due to the correspondence of the developed method of deposition and phosphating solution to protect reinforcing steel from corrosion and to the obtained experimental data to physicochemical ideas about the real picture of the mass transfer process during corrosion degradation and the results of previous studies of other authors.

\section{Results and discussion}

For the graphical method of calculating the speed and characteristics of the corrosion process, polarization diagrams are built: $E_{\mathrm{a}}-\mathrm{j}_{\mathrm{a}}$ is anodic polarization curve of the anode sections and $\mathrm{E}_{\mathrm{k}}$ $\mathrm{j}_{\mathrm{k}}$ is cathodic polarization curve of the cathode sections. The analysis of corrosion diagrams is reduced to the determination of the controlling process or the stage of the electrochemical corrosion process which has the greatest resistance compared to the other stages.

By the method of corrosion measurements experimental data were obtained in a $10 \% \mathrm{NaCl}$ solution for samples of steel grade St3 coated with and without protective phosphate films [11]. Corrosion diagrams are constructed on the basis of the obtained results (Fig. 1). 


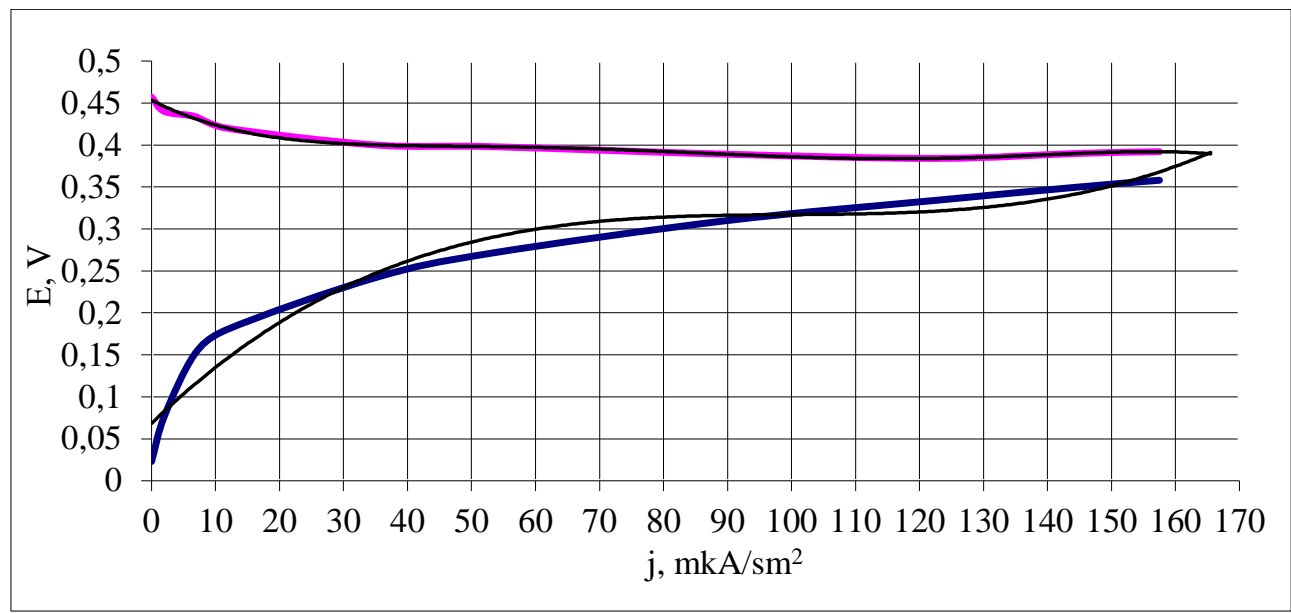

a)

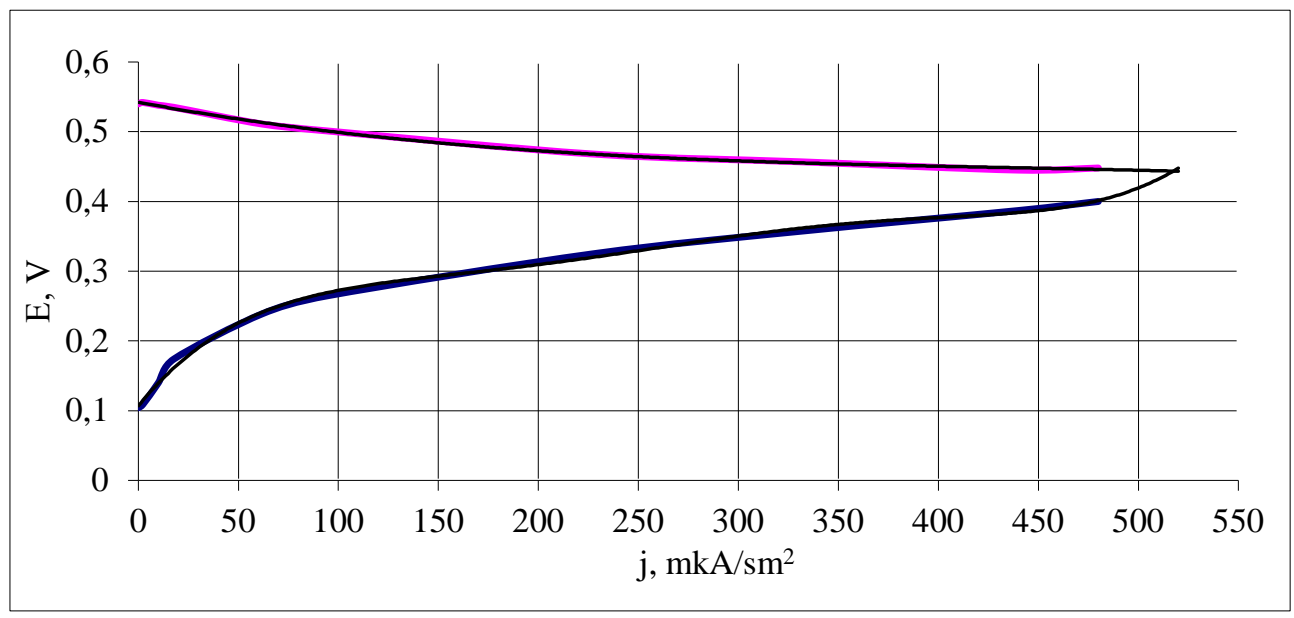

b)

Fig. 1. Corrosion diagram for steel grade St3 sample in $10 \% \mathrm{NaCl}$ solution: a) without protective coating b) with phosphate coating.

By the graphical method for the highest value of the achieved current the corrosion indicators of samples of steel grade St3 are determined [12] (Table 1).

$$
\begin{gathered}
C_{a}=\frac{\Delta \varphi_{a}}{\varphi_{p_{a}-} \varphi_{p_{\mathrm{K}}}} \cdot 100 \%, \\
C_{\mathrm{K}}=\frac{\Delta \varphi_{\mathrm{K}}}{\varphi_{p_{a}-} \varphi_{p_{\mathrm{K}}}} \cdot 100 \%, \\
K_{m}^{-}=\frac{I A}{z S \cdot 26,8}, \\
K_{h}=K_{m}^{-} \frac{8,76}{\rho_{m \mathrm{e}}}
\end{gathered}
$$

where: $C_{a}$ is degree of anode control, \%; $C_{k}$ is degree of cathode control, \%; $\Delta \varphi_{a}$ is anodic polarization, $\mathrm{V} ; \Delta \varphi_{k}$ is cathodic polarization, $\mathrm{V} ; \varphi_{p k}$ is initial value of cathode potential, $\mathrm{V} ; \varphi_{p a}$ is initial value of anode potential, $\mathrm{V} ; K^{-}{ }_{m}$ is negative rate of mass change, $\mathrm{g} / \mathrm{m}^{2} \cdot \mathrm{h} ; \mathrm{I}$ is corrosion 
current, $\mathrm{A} ; A$ is atomic mass of metal, $\mathrm{g} ; \mathrm{z}$ is valence of metal ion passing into solution; $S$ is anode surface, $\mathrm{m}^{2} ; K_{h}$ is depth index of corrosion, mm/year; $\rho_{m e}$ is metal density, $\mathrm{g} / \mathrm{sm}^{3}$.

Table 1. Test data for corrosion protection of phosphate coatings by contact corrosion

\begin{tabular}{|c|c|c|c|c|c|}
\hline $\begin{array}{c}\text { Steel } \\
\text { grade }\end{array}$ & $\begin{array}{c}\text { Sample surface } \\
\text { condition }\end{array}$ & $\begin{array}{c}\text { Degree of } \\
\text { anode } \\
\text { control } \mathrm{C}_{\mathrm{a}}, \\
\%\end{array}$ & $\begin{array}{c}\text { Degree of } \\
\text { cathode } \\
\text { control } \mathrm{C}_{\mathrm{K}}, \\
\%\end{array}$ & $\begin{array}{c}\text { The rate of } \\
\text { change in the } \\
\text { mass of the } \\
\text { sample } \\
\mathrm{K}^{-} \mathrm{m}, \mathrm{g} / \mathrm{m}^{2} \mathrm{~h}\end{array}$ & $\begin{array}{c}\text { Depth index of } \\
\text { corrosion, } \mathrm{K}, \\
\text { mm/year }\end{array}$ \\
\hline \multirow{2}{*}{ St3 } & Without coating & 12 & 88 & 0,56074 & 0,682 \\
\cline { 2 - 6 } & $\begin{array}{c}\text { Phosphate } \\
\text { coating }\end{array}$ & 30 & 70 & 0,1492 & 0,168 \\
\hline
\end{tabular}

The tests of the protective properties of phosphate coatings by contact corrosion method (Table 1) show that films with a finer crystal structure, as in modified phosphate coatings, are more resistant to anodic dissolution of steel [13]. The depth index of corrosion of modified phosphate coatings does not exceed $0,3 \mathrm{~mm} /$ year, and the permissible ranges is from 0,3 to $0,5 \mathrm{~mm}$ /year [14]. In addition, these results correlate with data that with increasing carbon content in steels their corrosion resistance decreases [15]. Apparently, this is due to the fact that with an increase in the carbon content, the number of metal - carbon-containing phase pairs increases. The more such pairs, the more likely and stronger corrosion.

During the experiment on the study of mass transfer processes occurring during liquid corrosion of reinforced concrete, in order to develop mathematical models for their description [12], the kinetics of the corrosion process of steel reinforcement with and without protective phosphate coatings for 150 days in solutions of various compositions [11] was studied. During the period of the experiment, the content of $\mathrm{Fe}^{2+}$ cations in solutions was determined by titrating samples of the test media with a solution of potassium permanganate. As can be seen in Fig. 2-4, in solutions with samples protected by phosphate films, the appearance of the first signs of the presence of iron cations occurs later than in samples not coated with films; the equilibrium state in such systems is achieved faster, the iron content at the time of equilibrium is lower..

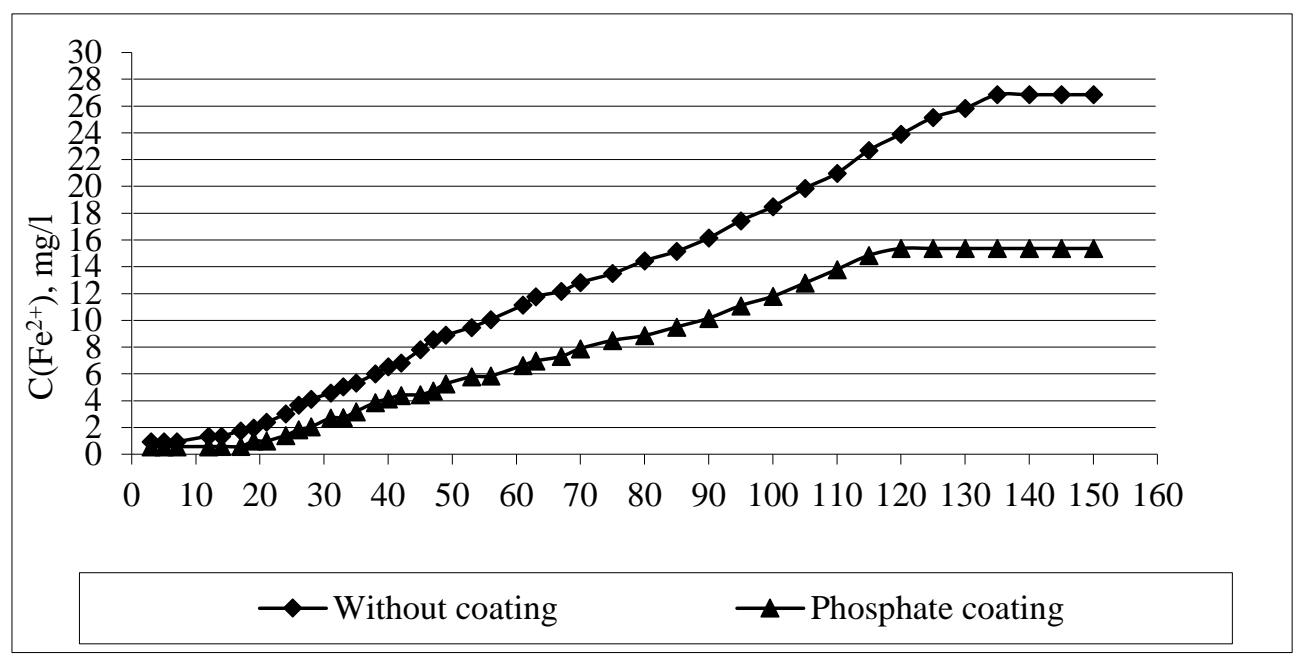

Fig. 2. Kinetic curves of steel reinforcement corrosion process in water. 


\section{ICMTMTE 2019}

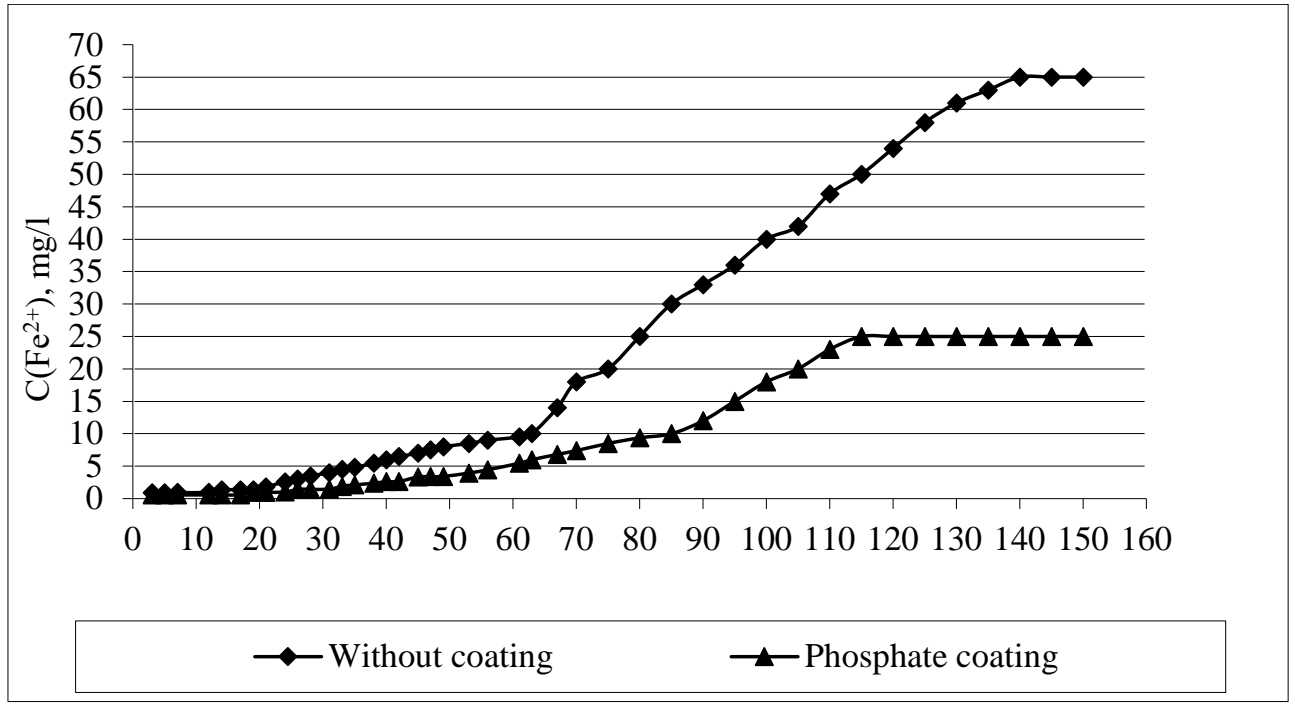

Fig. 3. Kinetic curves of steel reinforcement corrosion process in $2 \% \mathrm{MgCl}_{2}$ solution.

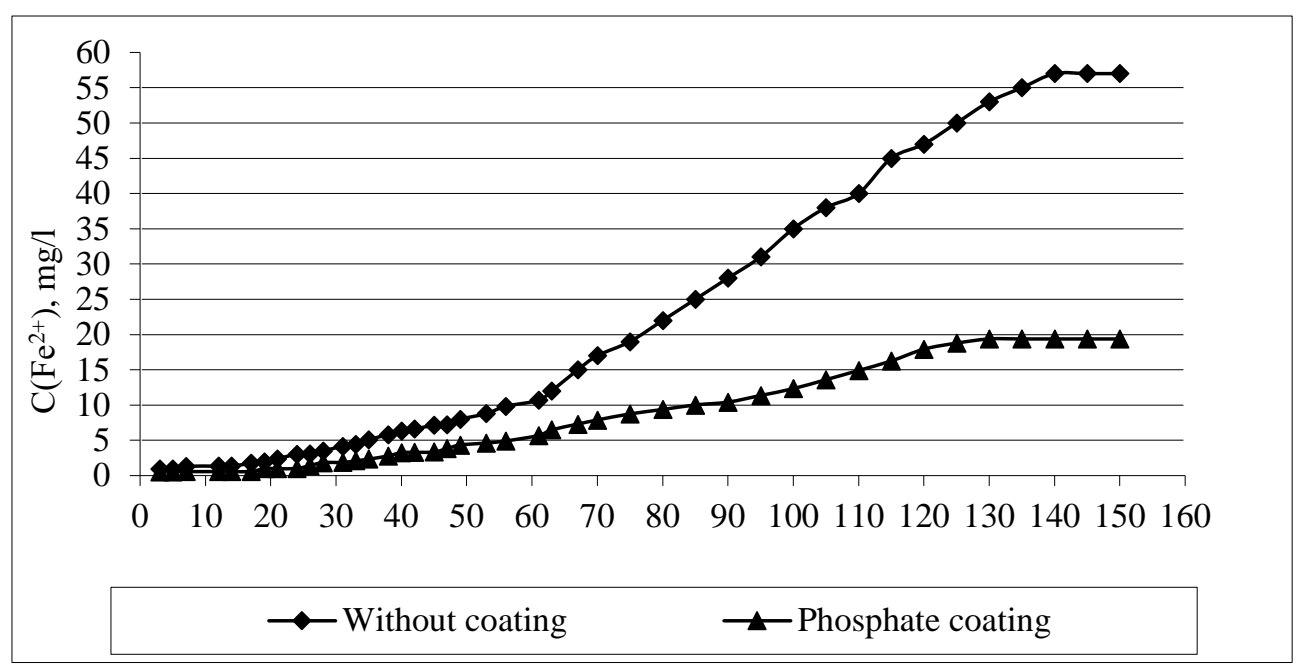

Fig. 4. Kinetic curves of steel reinforcement corrosion process in $\mathrm{HCl}$ solution ( $\mathrm{pH}=5)$.

The phosphate film mechanically prevent the effect of corrosive environment on steel. In violation of the continuity of the protective coating there are pockets of local corrosion. Modifiers introduced into the composition of phosphating solutions improve the anticorrosive properties of coatings, reduce the probability of cracking under the influence of internal stresses [16, 17].

The obtained results allow to calculate the main indicators of corrosion of steel reinforcement (Fig. 5). 


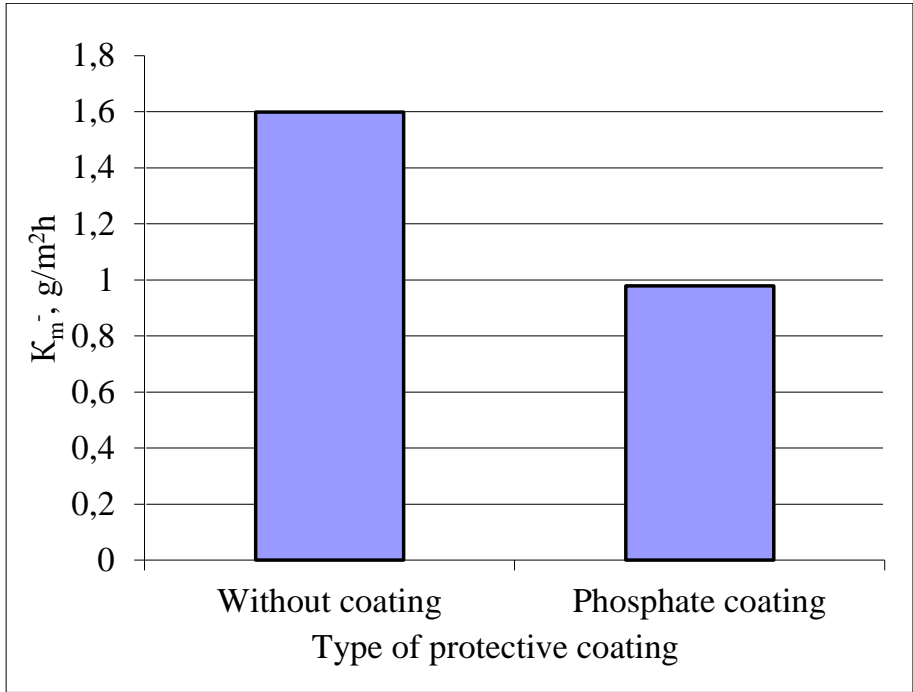

a)

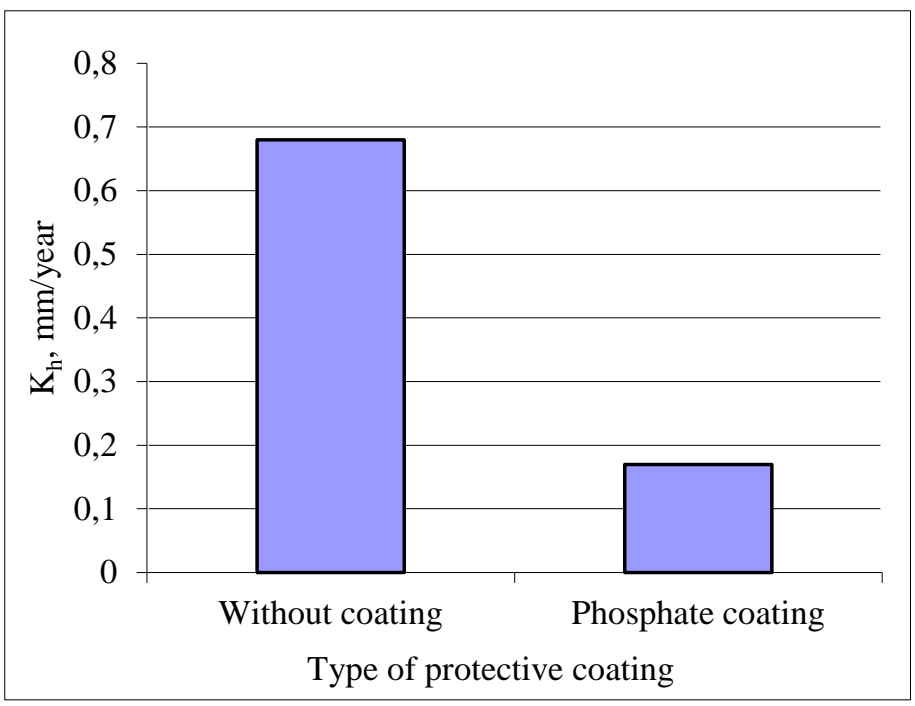

b)

Fig. 5. The corrosion rates: a - negative rate of change of the mass of the samples; $b$ - depth index of corrosion.

Mass losses of samples with modified coatings were 15-20 mg; for reinforcement without protection this value reached $65 \mathrm{mg}$.

In parallel to the determination of the content of iron ions in solutions, the potential of the samples was measured (Fig. 6-8) [18]. 


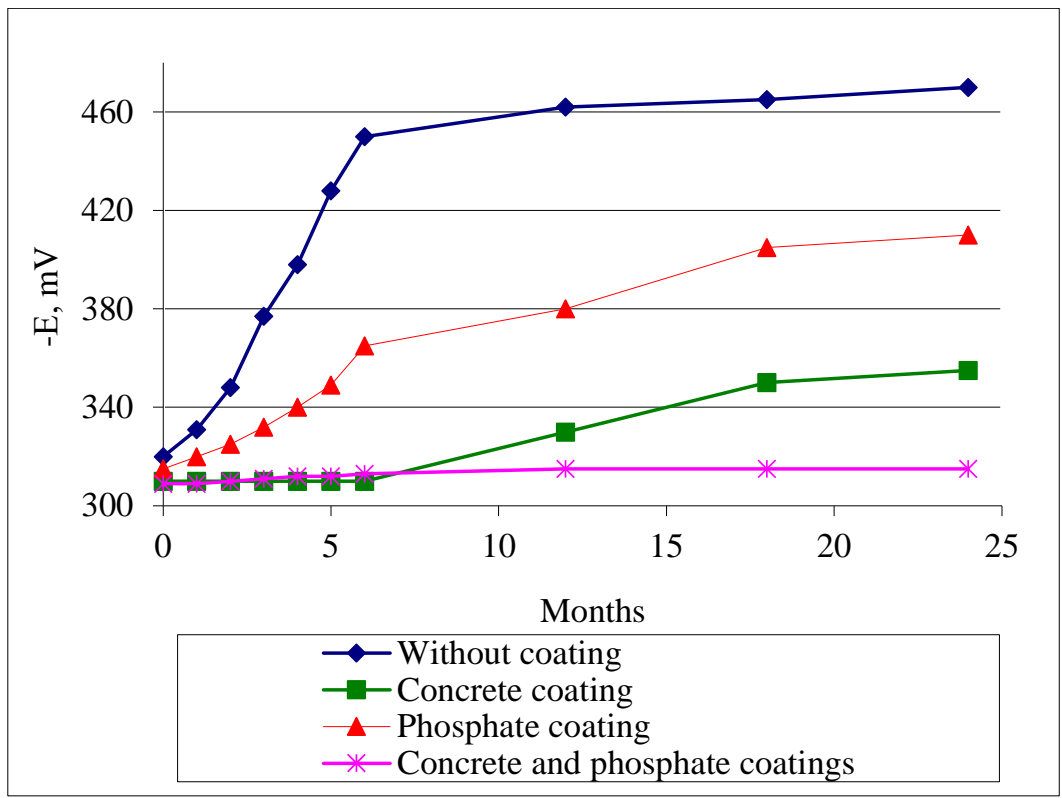

Fig. 6. Values of reinforcement potential in water.

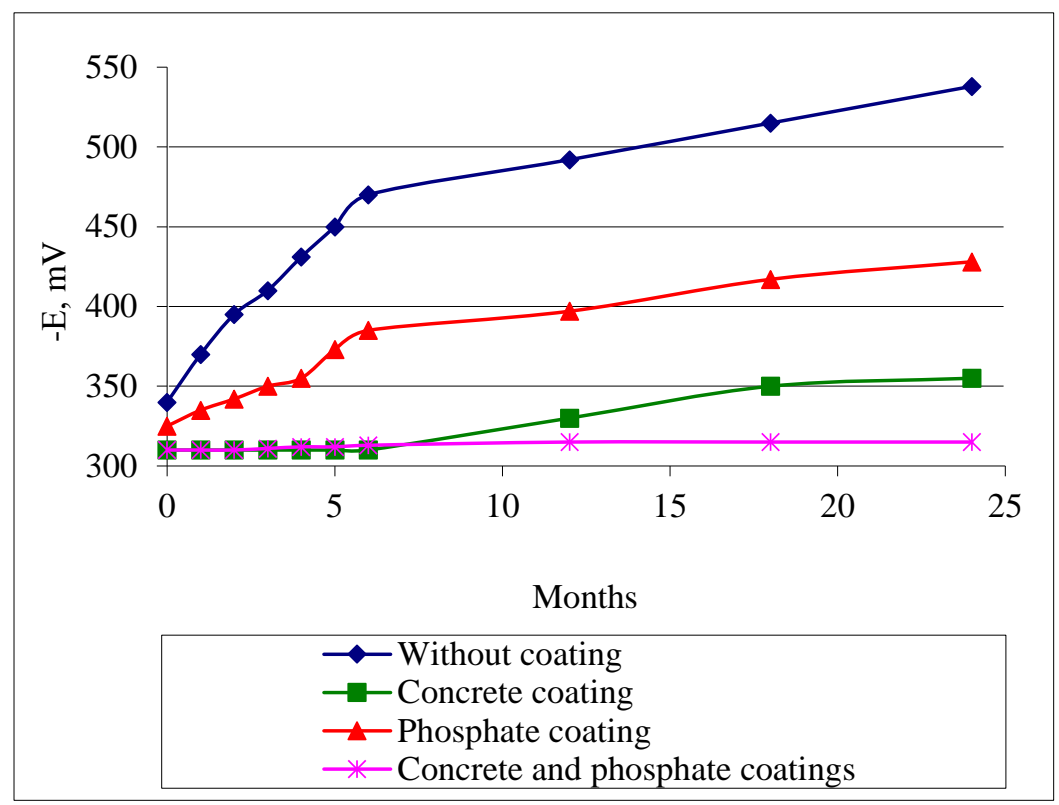

Fig. 7. Values of reinforcement potential in $\mathrm{HCl}$ solution $(\mathrm{pH}=5)$. 


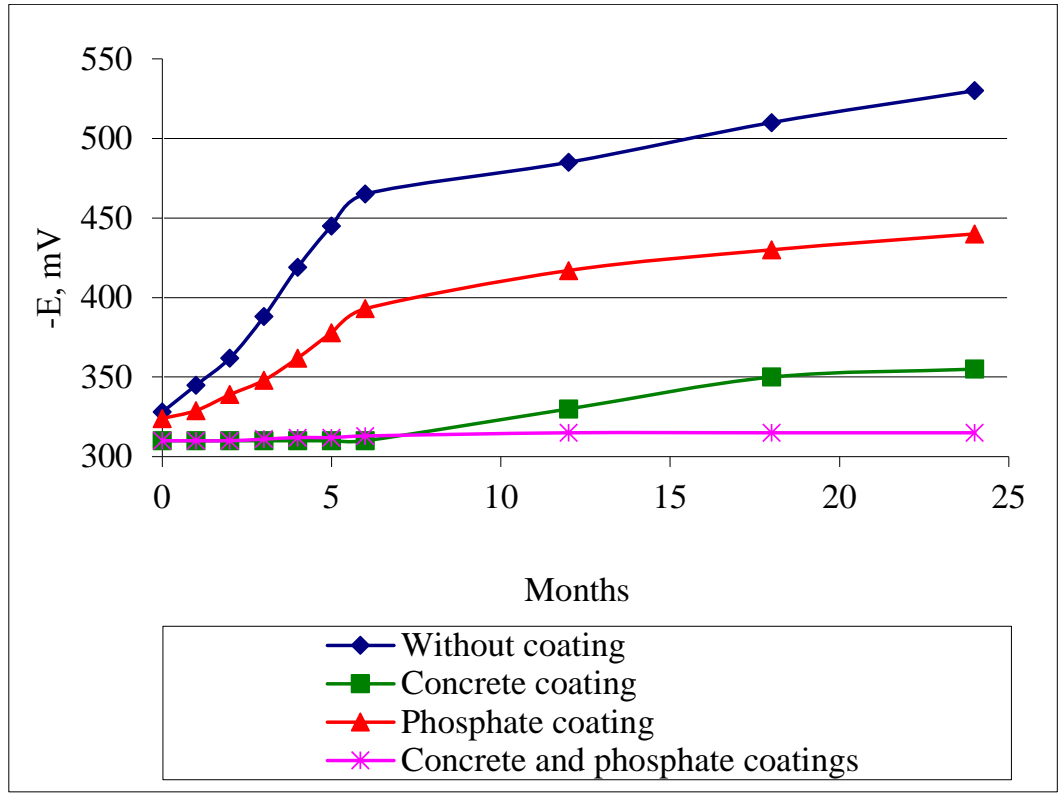

Fig. 8. Values of reinforcement potential in a $2 \% \mathrm{MgCl}_{2}$ solution.

In unprotected samples the change of electrode potential starts already at 14-15 days of finding them in a corrosive environment, and after 150 days the potential exceeds $-440 \mathrm{mV}$. Steel reinforcement protected by modified phosphate films retains the potential at $-320 \mathrm{mV}$ for 50 days. The protective properties of the coating are preserved. Further displacement of the potential in the negative direction is caused by the formation of the first foci of corrosion under the influence of chloride ions penetrating to the steel. In samples protected by phosphate films, the potential change is not as sharp as in samples without coating, and the "dilution" of steel is slower [18].

The change in the potential of the reinforcement under the protection of the cement coating begins after six months of finding samples in a corrosive environment. Then the electrode potential gradually decreases and after 18 months of testing there is a tendency to establish a constant potential of the reinforcement at the level of -350 to $-355 \mathrm{mV}$, which indicates the onset of equilibrium in the system «corrosive environment - concrete reinforcement» [18].

It is obvious that additional protection of reinforcement in concrete by applying a phosphate coating will provide the required durability of reinforced concrete structures in mass construction.

\section{References}

1. K. Tuutti, Corrosion of Steel in Concrete (Swedish foundation for concrete research, Stockholm, 1982)

2. Z.P. Bažant, Physical model for steel corrosion in concrete sea structures, Journal of the Structural Division, 105 (ST6), pp. 1137-1166 (1979)

3. S.N. Leonovich, A.V. Prasol, Models of the period of initiation of reinforcement corrosion, Construction and building materials, 9, pp. 74-75 (2012)

4. L. Bertolini, B. Elsener, Corrosion of Steel in Concrete. Prevention, Diagnosis, Repair (Viernheim, Wiley, 2004) 
5. Mohamed El-Reedy, Steel-reinforced concrete structures: assessment and repair of corrosion (Taylor \& Francis Group, 2008)

6. J.G. Dai, Y. Akira, F.H. Wittmann, H. Yokota, P. Zhang, Water repellent surface impregnation for extension of service life of reinforced concrete structures in marine environments: the role of cracks, Cement and Concrete Composites, vol. 32, 2, pp. 101109 (2010)

7. L.J. Parrot, Steel corrosion in concrete: How does it occur? Materials Protection, vol. 6, 11, pp. 19-23 (1967)

8. N.K. Rozental, V.F. Stepanova, G.V. Chehniy, Chlorides in Concrete and Their Impact on D evelopment of Corrosion of Steel Reinforcement, Industrial and civil engineering, 1, pp. 92-96 (2017)

9. I.A. Kazarinov, L.A. Isaycheva, Makhmmod A. Adiba, N.M. Trepak, Chemical Phosphatizing of Carbon Steel, Protection of Metals and Physical Chemistry of Surfaces, vol. 55, 4, pp. 700-705 (2019)

10. O.V. Nemykina, M.V. Davydkin, Researching corrosion resistance of steel with METAC phosphate coating, Proceedings of Irkutsk State Technical University, 3 (74), pp. 85-88 (2013)

11. S.V. Fedosov, V.Ye. Rumyantseva, K.Ye. Rumyantseva, V.S. Konovalova, M.Ye. Shesterkin, Features of cold bonderization of reinforcing steel, Bulletin of Civil Engineers, 2 (31), pp. 79-82 (2012)

12. V.E. Rumyantseva, V.S. Konovalova, N.M. Vitulova, Corrosion inhibition of reinforced concrete structures, Building and reconstruction, 4 (54), pp. 65-72 (2014)

13. V.E. Rumyantseva, K.E. Rumyantseva, V.S. Konovalova, The influence of cold phosphating modifiers on corrosion stability of steels, Building and reconstruction, 3 (47), pp. 64-68 (2013)

14. U.R. Evans, The Corrosion and Oxidation of Metals: Scientific Principles and Practical Applications (St. Martin's Press, 1960)

15. V.E. Rumyantseva, V.S. Konovalova, The effect of inhibitors introduced into concrete on corrosion of concrete steel reinforcement, Problems of Contemporary Science and Practice. Vernadsky University, 1 (59), pp. 29-34 (2016)

16. N.V. Danyakin, A.A. Sigida, Methods and mechanisms of application of corrosion inhibitors of metals and alloys, Auditorium, 2 (14), pp. 132-140 (2017)

17. V.N. Selivanov, Yu.P. Perelygin, The universal phosphating solution, University proceedings. Volga region. Natural Sciences, 1 (2), pp. 135-143 (2013)

18. S.V. Fedotov, V.Ye. Rumyantseva, V.S. Konovalova, Study of corrosion destruction processes of reinforced concrete products in aggressive environments containing chloride ions, Bulletion of Civil Engineers, 5 (58), pp. 61-67 (2016) 